\title{
Age-related hearing loss in individuals and their caregivers: effects of coping on the quality of life among the dyads
}

This article was published in the following Dove Press journal:

Patient Preference and Adherence

7 November 2016

Number of times this article has been viewed

\section{Sébastien Lazzarotto ${ }^{1,2}$ \\ Karine Baumstarck' \\ Anderson Loundou' \\ Zeinab Hamidou' ${ }^{1,3}$ \\ Valérie Aghababian' \\ Tanguy Leroy ${ }^{1,4}$ \\ Pascal Auquier}

'EA 3279, Self-Perceived Health Assessment Research Unit, School of Medicine, Aix Marseille Université, ${ }^{2}$ French Regional Institute for Prevention of Aging, Marseille, ${ }^{3}$ National Clinical Research Quality of Life in Oncology Platform, Marseille, ${ }^{4}$ Social Psychology Research Group (GRePS EA 4I63), Université Lumière Lyon 2, Bron, France
Correspondence: Karine Baumstarck EA 3279, Self-Perceived Health Assessment Research Unit, School of Medicine, Aix Marseille Université, 27 Boulevard Jean Moulin, Marseille Cedex 05, F-13385, France

Tel +33491384744

Fax +33 49I 384482

Email karine.baumstarck@univ-amu.fr
Objectives: Age-related hearing loss (ARHL) impacts the daily living and quality of life (QoL) of affected individuals and the functioning of family caregivers. In the specific context of voluntary medical checkups, we examined sample dyads (ARHL individual and the caregiver) to determine whether QoL of patients and caregivers is influenced by coping strategies implemented either by themselves or their relatives.

Methods: This was a cross-sectional study with a descriptive/correlative design performed in a French preventive health center (Regional Institute for Prevention of Aging, Marseille, France) for the beneficiaries of pension funds of private sector employees. The samples included beneficiary-caregiver dyads. The beneficiaries had bilateral (mild to moderately severe) ARHL Self-reported data were collected as follows: QoL using the World Health Organization Quality of Life questionnaire, coping strategies using the Brief Coping Orientation to Problems Experienced Scale, and anxiety and mood using visual analog scales.

Results: The final sample comprised 44 beneficiaries and 44 caregivers. The caregiver was the partner of the beneficiary in $73 \%$ of cases. The QoL scores of the social dimension were significantly lower for beneficiaries and caregivers compared with French age- and sex-matched controls. Among beneficiaries and caregivers, coping strategies based on problem solving were the most commonly used strategies. The use of positive thinking strategies was associated with higher QoL scores. The more one member of the dyad used an avoidance coping strategy, the more the other member used a positive thinking strategy.

Conclusion: This study emphasizes that QoL of individuals with age-related hearing impairment and their natural caregivers is related to the coping strategies that they use. This finding suggests that targeted interventions should be offered to help individuals who experience emotional difficulties to implement more efficient coping strategies.

Keywords: age-related hearing impairment, caregivers, dyads, quality of life, coping, emotional status

\section{Introduction}

Hearing impairment is one of the most common disabilities in humans, affecting more than 250 million people worldwide. ${ }^{1}$ In France, its prevalence has been increasing: five million individuals are hearing impaired, which corresponds to $8 \%$ of the French population. Furthermore, $70 \%$ of the hearing-impaired people are over 60 years of age. ${ }^{2}$ Aging is the most common cause of hearing impairment and is referred to as age-related hearing loss (ARHL).

The consequences of ARHL include difficulty interpreting speech sounds, which often results in a reduced ability to communicate, as well as impaired physical and 
social functions. This can lead to cognitive deficits, mood disturbances, social isolation, and stigmatization. ${ }^{3}$ Some authors have reported on the impact of hearing loss on the social/familial life of individuals ${ }^{4-7}$ and on the quality of life (QoL) of individuals. ${ }^{8,9}$ It is now well documented that ARHL affects relatives' functioning in everyday life, ${ }^{10}$ specifically the main family caregiver. They need to exert more effort to communicate with the hearing-impaired individual, repeating themselves, speaking more slowly and loudly, and moving closer to them to be heard and obtain their attention. As a result of the partner's hearing loss, the caregivers reported anxiety and stress, limitations of verbal communication and intimacy with their relative, changes in social activities, avoidance of social gatherings, and feelings of isolation, frustration, resentment, and guilt, which ultimately reduced their own QoL. ${ }^{11-13}$

Therefore, because they must confront a disability that produces progressive lifestyle changes, it is important to study how ARHL individuals and caregivers handle the problems of daily life and how the ability to cope with difficulties actually impacts QoL. Coping is commonly defined as the cognitive and behavioral efforts that are implemented to solve the problems and reduce the stress that these problems may cause. ${ }^{14,15}$ The literature generally distinguishes active and avoidant coping strategies. ${ }^{16}$ Active coping strategies are thought to be better methods to address stressful events, and avoidant coping strategies appear to be a psychological risk factor for adverse responses to stressful life events. ${ }^{16}$

In the specific context of a voluntary medical checkup, we examined a sample of dyads that included the ARHL individual and his/her main caregiver to determine whether QoL of individuals is influenced by the coping strategies implemented either by themselves or their relatives.

\section{Methods}

\section{Design and settings}

We conducted a cross-sectional study with a descriptive/ correlative design. The recruitment of dyads (ARHL individual and caregiver) was made in a French preventive health center (Institut Régional d'Information et de Prévention de la Sénescence, Marseille, France, nonprofit association, law 1901). This center is affiliated with the pension funds of private sector employees (Association générale des institutions de retraite complémentaire des cadres and l'Association pour le régime de retraite complémentaire des salariés, http:// www.agirc-arrco.fr/l-agirc-et-larrco/). This center performs 3,000 annual health checkups for beneficiaries and/or partners of these beneficiaries, including medical, psychosocial, and cognitive prevention. The visit lasts a half day. A healthy diet and physical activity are systematically promoted.

\section{Sample selection}

The samples included beneficiary-caregiver dyads. The selection criteria for the beneficiaries were as follows: age above 55 years, having bilateral (conductive and/or sensorineural) ARHL, having a degree of hearing loss from mild ( $\geq 21 \mathrm{~dB})$ to moderately severe $(<70 \mathrm{~dB})$ according to the Clark's classification, ${ }^{17}$ ability to speak/read French, and agreeing to participate. The selection criteria of the caregivers were as follows: aged above 18 years, designated by the beneficiary as the most involved person in his/her life, able to speak/or read French, and agreeing to participate.

\section{Data collection}

Enrollment was performed on the day of the prevention visit. For the beneficiary, the following clinical data were gathered using their medical records and an examination by a doctor of the center: dizziness, tinnitus, visual deficit, and chronic disease. The nature of the relationship between the beneficiary and caregiver was recorded as the partner, child, or other. The age, sex, educational level, marital status, and professional status were recorded for both the beneficiary and his/her caregiver.

Self-reported data, including QoL, emotional status, and coping strategies, were collected by means of questionnaires that were completed by the beneficiaries and caregivers.

- QoL was assessed using the French version of the World Health Organization Quality of Life (WHOQoL) questionnaire, which is a generic questionnaire used worldwide, ${ }^{18,19}$ that describes four domains: physical health, psychological health, social relationships, and environment.

- Coping strategies were assessed using the Brief Coping Orientation to Problems Experienced Scale (BriefCope). ${ }^{20,21}$ This questionnaire includes 28 items that explore the following 14 strategies: self-distraction, active coping, denial, substance use, use of emotional support, use of instrumental support, behavioral disengagement, venting, positive reframing, planning, humor, acceptance, religion, and self-blame. Confirmatory factor analyses conducted among cancer patients and caregivers (Baumstarck unpublished data 2016) have shown a satisfactory goodness of fit, encouraging a reduction to four dimensions that include social support, problem solving, avoidance, and positive thinking. Higher scores in these 
four dimensions reflect a higher tendency to implement the corresponding coping strategies.

- Anxiety and mood were assessed using visual analog scales that ranged from 0 to 100 . Higher scores indicated a higher level of anxiety and a greater likelihood of mood disorders.

\section{Ethics}

Regulatory monitoring was performed in accordance with the French law that requires the approval of a French ethics committee (Comité d'éthique, Aix Marseille University, February 4, 2015, Number 2014-02-04-04). Written consent forms to participate in the study were obtained from every beneficiary and caregiver.

\section{Statistical aspects}

Due to the exploratory nature of the study, there was any sample size calculation. The study was proposed to all consecutive eligible participants during the study period. After performing descriptive analyses of the characteristics of beneficiaries and caregivers, QoL scores were computed using the algorithms provided by the developers of the tool. The WHOQoL scores of beneficiaries and caregivers were compared to those obtained from French age (six classes)- and sex (women/men)-matched controls from a normal sample of 16,392 subjects. ${ }^{19}$ The scores of coping were provided in the four scores corresponding to a four-factor structure that was previously explored by our team. Comparisons between the scores of beneficiaries and caregivers (QoL, coping strategies, anxiety, and mood) were performed using the Wilcoxon test. To assess the relationships between the QoL scores and coping processes for beneficiaries and caregivers, respectively, Spearman's correlations were performed. Bootstrapping estimates of parameter standard errors were collected to obtain robust standard error estimates and confidence intervals. The bootstrap percentile approach was used to calculate $95 \%$ confidence intervals, which generated 1,000 bootstrap subsamples.

\section{Results}

\section{Sample}

During the period between February 2015 and July 2015, 51 beneficiaries agreed to participate in the present study and provided written informed consent. We experienced no refusals. Of the 51 beneficiaries, 44 nominated a caregiver who agreed to participate. Therefore, the final sample was composed of 44 beneficiaries and 44 caregivers who were assessed a maximum of 2 weeks after the prevention visit and their main characteristics are presented in Table 1 . The caregiver was the partner of the beneficiary for $73 \%$, the child for $9 \%$, and the parent for $5 \%$ of the cases. The mean duration of completion was 15 minutes.

\section{QoL, coping strategies, and emotional status of the beneficiaries and caregivers}

The QoL scores of beneficiaries and caregivers are provided in Figure $1 \mathrm{~A}$ and $\mathrm{B}$, respectively. Of the three dimensions of the WHOQoL for which French norms are available, ${ }^{19}$ the scores of the social dimension were significantly lower for beneficiaries and caregivers compared with age- and sex-matched controls. The respective four QoL scores of beneficiaries did not differ from those of caregivers (all $P$-values $>0.05$ ).

Globally, beneficiaries and caregivers used the four types of coping strategies at similar levels (Figure 2). Among

Table I Sample characteristics

\begin{tabular}{|c|c|c|}
\hline & $\begin{array}{l}\text { Patients } \\
(\mathbf{N}=44) \\
\text { n (\%) }\end{array}$ & $\begin{array}{l}\text { Caregivers } \\
(\mathrm{N}=44) \\
\mathrm{n}(\%)\end{array}$ \\
\hline \multicolumn{3}{|l|}{ Sex } \\
\hline Females & $19(43)$ & $27(6 \mathrm{I})$ \\
\hline Males & $25(57)$ & $17(39)$ \\
\hline \multicolumn{3}{|l|}{ Age } \\
\hline Mean \pm SD & $70.63 \pm 9.47$ & $64.4 \pm 12.79$ \\
\hline Min-max & $57-93$ & $19-87$ \\
\hline \multicolumn{3}{|l|}{ Marital status } \\
\hline Single & $8(18)$ & $7(16)$ \\
\hline Couple & $36(82)$ & $37(84)$ \\
\hline \multicolumn{3}{|l|}{ People living at home } \\
\hline 0 & $9(2 I)$ & $7(16)$ \\
\hline$\geq 1$ & $35(79)$ & $36(39)$ \\
\hline \multicolumn{3}{|l|}{ Children at home } \\
\hline No & $37(84)$ & $29(83)$ \\
\hline Yes & $5(16)^{\prime}$ & $6(17)$ \\
\hline \multicolumn{3}{|l|}{ Educational level } \\
\hline Low (<12 years) & $26(59)$ & $17(39)$ \\
\hline High ( $\geq 12$ years) & $18(4 I)$ & $24(6 I)$ \\
\hline \multicolumn{3}{|l|}{ Chronic disease } \\
\hline No & $27(64)$ & $30(68)$ \\
\hline Yes & $15(36)$ & $14(32)$ \\
\hline \multicolumn{3}{|l|}{ Visual deficit } \\
\hline No & $24(57)$ & $24(54)$ \\
\hline Yes & $18(43)$ & $20(46)$ \\
\hline \multicolumn{3}{|l|}{ Hearing aid use } \\
\hline No & $13(33)$ & $\mathrm{N} / \mathrm{A}$ \\
\hline Yes & $26(67)$ & $\mathrm{N} / \mathrm{A}$ \\
\hline \multicolumn{3}{|l|}{ Tinnitus } \\
\hline No & $25(57)$ & $N / A$ \\
\hline Yes & $19(43)$ & $\mathrm{N} / \mathrm{A}$ \\
\hline \multicolumn{3}{|l|}{ Dizziness } \\
\hline No & $33(75)$ & $N / A$ \\
\hline Yes & $11(25)$ & $N / A$ \\
\hline
\end{tabular}

Abbreviations: SD, standard deviation; min-max, minimum-maximum; N/A, not applicable. 

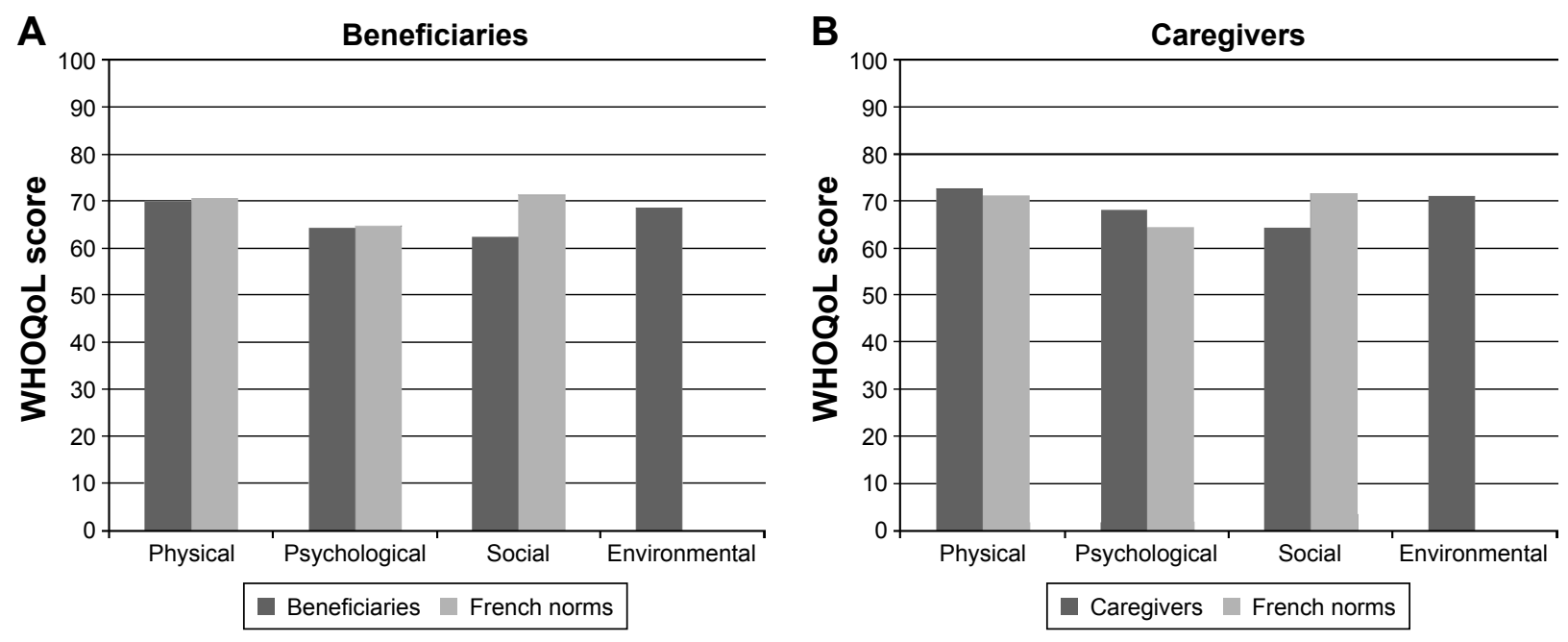

Figure I Comparisons (A) beneficiaries, (B) caregivers, of WHOQoL scores between the participants and French age- and sex-matched norms. Note: The higher the scores, the higher the QoL level. Data from Baumann et al. ${ }^{19}$ Abbreviation: WHOQoL, World Health Organization Quality of Life.

beneficiaries and caregivers, the strategies that were based on social support and avoidance were the least used strategies, and the strategies based on problem solving were the most used strategies. The mean levels of anxiety and mood disorders did not differ between beneficiaries and caregivers (anxiety: $5.0 \pm 3.0$ vs $5.0 \pm 3.1, P=0.971$; mood: $3.7 \pm 2.7$ vs $4.2 \pm 3.1, P=0.406)$.

\section{Relationships between emotional status, coping strategies, and QoL for beneficiaries}

As expected, the anxiety and mood disorder scores were significantly and negatively correlated with the respective psychological and physical QoL scores (coefficients ranged from -0.39 to -0.56 ). When beneficiaries used positive

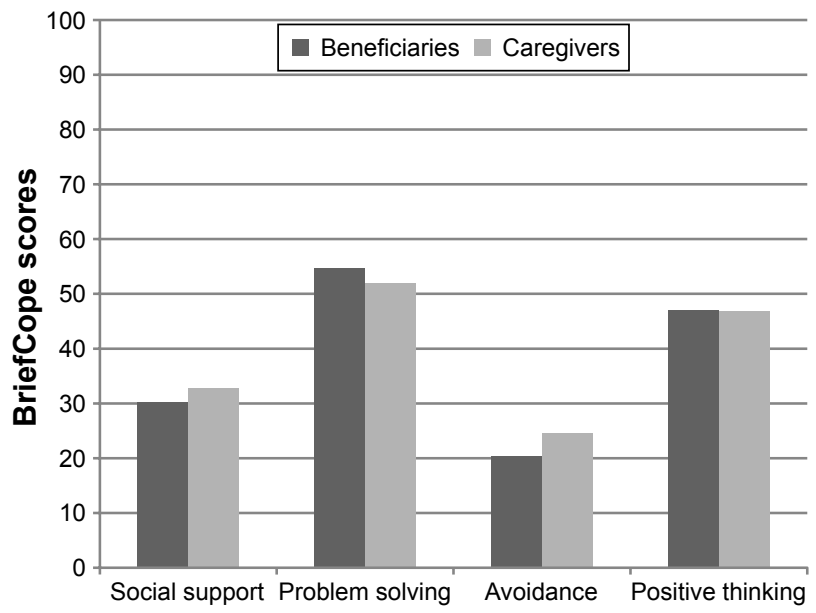

Figure 2 Coping strategies used by patients and caregivers. Note: Scores ranged from 0 to 100 . thinking strategies, they reported significantly higher QoL scores in all dimensions; when they used problem-solving strategies, they reported significantly higher QoL scores in the physical and psychological dimensions. Being avoidant and using social support seeking strategies were not associated with QoL. All the correlations are detailed in Table 2.

\section{Relationships between emotional status, coping strategies, and QoL for caregivers}

The anxiety and mood disorder scores were significantly and negatively correlated with the respective psychological and social QoL scores. The physical QoL score correlated with the anxiety level. When implemented by caregivers, problem-solving and positive thinking coping strategies were significantly associated with all of the caregiver QoL scores (except for positive thinking strategies and the social QoL score, and problem-solving and the environmental QoL scores). Being avoidant and using social support strategies were not associated with QoL. All the correlations are detailed in Table 3.

\section{Interrelations between beneficiaries and their caregivers for coping strategies and QoL}

The social and environmental QoL scores of beneficiaries and caregivers were correlated, but not the physical and psychological QoL scores. The psychological QoL score of the caregiver was linked to the environmental QoL score of the patient. The more the caregiver used an avoidance coping strategy, the more the patient used a positive thinking 
Table 2 Relationships between QoL scores and emotional status and coping strategies for patients

\begin{tabular}{|c|c|c|c|c|}
\hline & \multicolumn{4}{|c|}{ Quality of life (WHOQoL) } \\
\hline & Physical & Psychological & Social & Environment \\
\hline \multicolumn{5}{|c|}{ Emotional status ${ }^{\mathrm{a}}$} \\
\hline \multicolumn{5}{|l|}{ Anxiety } \\
\hline Sample & $-0.407 * *$ & $-0.389 *$ & -0.220 & -0.250 \\
\hline Bootstrap bias & 0.017 & 0.005 & 0.002 & 0.010 \\
\hline $95 \% \mathrm{Cl}$ & $(-0.615,-0.134)$ & $(-0.623,-0.088)$ & $(-0.492,0.076)$ & $(-0.535,0.082)$ \\
\hline \multicolumn{5}{|l|}{ Mood disorders } \\
\hline Sample & $-0.453 * *$ & $-0.560 * *$ & -0.213 & -0.178 \\
\hline Bootstrap bias & 0.010 & 0.011 & 0.014 & 0.001 \\
\hline $95 \% \mathrm{Cl}$ & $(-0.688,-0.154)$ & $(-0.740,-0.309)$ & $(-0.483,0.149)$ & $(-0.490,0.161)$ \\
\hline \multicolumn{5}{|c|}{ Coping strategies $^{\mathrm{b}}$} \\
\hline \multicolumn{5}{|c|}{ Social support } \\
\hline Sample & -0.205 & 0.153 & 0.272 & 0.047 \\
\hline Bootstrap bias & 0.002 & -0.006 & -0.007 & -0.001 \\
\hline $95 \% \mathrm{Cl}$ & $(-0.490,0.114)$ & $(-0.168,0.420)$ & $(-0.096,0.570)$ & $(-0.266,0.345)$ \\
\hline \multicolumn{5}{|l|}{ Problem solving } \\
\hline Sample & $0.38 I^{*}$ & $0.506 * *$ & 0.246 & 0.125 \\
\hline Bootstrap bias & 0.005 & -0.006 & 0.003 & 0.000 \\
\hline $95 \% \mathrm{Cl}$ & $(0.080,0.650)$ & $(0.214,0.726)$ & $(-0.060,0.524)$ & $(-0.167,0.425)$ \\
\hline \multicolumn{5}{|l|}{ Avoidance } \\
\hline Sample & -0.065 & 0.026 & 0.094 & -0.042 \\
\hline Bootstrap bias & 0.000 & -0.002 & -0.005 & 0.002 \\
\hline $95 \% \mathrm{Cl}$ & $(-0.338,0.26 \mathrm{I})$ & $(-0.258,0.298)$ & $(-0.189,0.370)$ & $(-0.322,0.253)$ \\
\hline \multicolumn{5}{|l|}{ Positive thinking } \\
\hline Sample & $0.473 * *$ & $0.467 * *$ & $0.317^{*}$ & $0.322^{*}$ \\
\hline Bootstrap bias & -0.007 & -0.007 & -0.005 & -0.003 \\
\hline $95 \% \mathrm{Cl}$ & $(0.226,0.681)$ & $(0.16 \mathrm{I}, 0.708)$ & $(-0.009,0.599)$ & $(0.0|4,0.6| 4)$ \\
\hline
\end{tabular}

Notes: a VAS (visual analog scale) from 0 (less) to 10 (high level); ${ }^{b}$ coping strategies from the BriefCope questionnaire. $* P<0.05$, $* * P<0.01$.

Abbreviations: WHOQoL, World Health Organization Quality of Life; Cl, confidence interval; BriefCope, Brief Coping Orientation to Problems Experienced Scale.

Table 3 Relationships between QoL scores and emotional status and coping strategies for caregivers

\begin{tabular}{|c|c|c|c|c|}
\hline & \multicolumn{4}{|c|}{ Quality of life (WHOQoL) } \\
\hline & Physical & Psychological & Social & Environment \\
\hline \multicolumn{5}{|c|}{ Emotional status ${ }^{\mathrm{a}}$} \\
\hline \multicolumn{5}{|l|}{ Anxiety } \\
\hline Sample & $-0.319 *$ & $-0.644 * *$ & -0.519 ** & -0.289 \\
\hline Bootstrap bias & 0.012 & 0.018 & 0.003 & 0.002 \\
\hline $95 \% \mathrm{Cl}$ & $(-0.564,-0.018)$ & $(-0.770,-0.434)$ & $(-0.676,-0.323)$ & $(-0.561,-0.002)$ \\
\hline \multicolumn{5}{|l|}{ Mood disorders } \\
\hline Sample & $-0.27 \mid$ & $-0.730 * *$ & $-0.380 *$ & -0.259 \\
\hline Bootstrap bias & 0.005 & 0.007 & 0.005 & 0.000 \\
\hline $95 \% \mathrm{Cl}$ & $(-0.57 \mathrm{I}, 0.040)$ & $(-0.84 I,-0.566)$ & $(-0.596,-0.140)$ & $(-0.527,0.042)$ \\
\hline \multicolumn{5}{|c|}{ Coping strategies $^{\mathrm{b}}$} \\
\hline \multicolumn{5}{|c|}{ Social support } \\
\hline Sample & 0.089 & -0.206 & 0.124 & -0.029 \\
\hline Bootstrap bias & -0.011 & 0.004 & -0.010 & 0.001 \\
\hline $95 \% \mathrm{Cl}$ & $(-0.229,0.345)$ & $(-0.495,0.076)$ & $(-0.230,0.428)$ & $(-0.327,0.271)$ \\
\hline \multicolumn{5}{|l|}{ Problem solving } \\
\hline Sample & $0.317^{*}$ & $0.418 * *$ & $0.338^{*}$ & 0.348 \\
\hline Bootstrap bias & 0.006 & 0.000 & -0.006 & -0.012 \\
\hline $95 \% \mathrm{Cl}$ & $(-0.029,0.609)^{*}$ & $(0.119,0.675)$ & $(0.020,0.606)$ & $(0.007,0.625)$ \\
\hline \multicolumn{5}{|l|}{ Avoidance } \\
\hline Sample & -0.020 & -0.204 & -0.037 & 0.059 \\
\hline Bootstrap bias & 0.011 & 0.001 & 0.001 & 0.002 \\
\hline $95 \% \mathrm{Cl}$ & $(-0.320,0.3 \mathrm{II})$ & $(-0.489,0.097)$ & $(-0.380,0.294)$ & $(-0.252,0.351)$ \\
\hline \multicolumn{5}{|l|}{ Positive thinking } \\
\hline Sample & $0.359 *$ & $0.558 * *$ & 0.221 & $0.532 * *$ \\
\hline Bootstrap bias & -0.006 & -0.010 & 0.000 & -0.008 \\
\hline $95 \% \mathrm{Cl}$ & $(0.067,0.616)$ & $(0.245,0.763)$ & $(-0.128,0.536)$ & $(0.256,0.7 \mid 3)$ \\
\hline
\end{tabular}

Notes: ${ }^{\mathrm{V}} \mathrm{VAS}$ (visual analog scale) from 0 (less) to 10 (high level); bcoping strategies from the BriefCope questionnaire. $* P<0.05$, $* * P<0.01$.

Abbreviations: WHOQoL, World Health Organization Quality of Life; Cl, confidence interval; BriefCope, Brief Coping Orientation to Problems Experienced Scale. 
strategy. The more the caregiver used a social support coping strategy, the more the patient used a problem-solving strategy. When the patient's use of social support strategies increased, the physical QoL score of the caregiver was higher; similarly, when the caregiver's use of social support strategies increased, the physical QoL score of the patient was higher. The more the caregivers used problem-solving strategies, the higher were the environmental QoL scores for their beneficiaries, and the more the caregivers used positive thinking strategies, the higher were the social QoL scores for their beneficiaries. All these results are presented in Table 4.

Table 4 Relationships between caregivers' and patients' scores

\begin{tabular}{|c|c|c|c|c|c|c|c|c|}
\hline \multirow[t]{3}{*}{ Patients } & \multicolumn{8}{|c|}{ Caregivers } \\
\hline & \multicolumn{4}{|c|}{ WHOQoL } & \multicolumn{4}{|l|}{ Copinga } \\
\hline & Physical & Psychological & Social & Environment & $\begin{array}{l}\text { Social } \\
\text { support }\end{array}$ & $\begin{array}{l}\text { Problem } \\
\text { solving }\end{array}$ & Avoidance & $\begin{array}{l}\text { Positive } \\
\text { thinking }\end{array}$ \\
\hline \multicolumn{9}{|l|}{ WHOQOL } \\
\hline \multicolumn{9}{|l|}{ Physical } \\
\hline Sample & -0.165 & 0.074 & 0.093 & 0.203 & $0.36 I^{*}$ & 0.209 & -0.058 & 0.101 \\
\hline Bootstrap bias & 0.001 & -0.007 & -0.004 & 0.000 & -0.014 & -0.005 & 0.007 & -0.002 \\
\hline $95 \% \mathrm{Cl}$ & $\begin{array}{l}(-0.444 \\
0.142)\end{array}$ & $\begin{array}{l}(-0.245 \\
0.368)\end{array}$ & $\begin{array}{l}(-0.185, \\
0.342)\end{array}$ & $\begin{array}{l}(-0.119 \\
0.474)\end{array}$ & $\begin{array}{l}(0.067, \\
0.588)\end{array}$ & $\begin{array}{l}(-0.084 \\
0.487)\end{array}$ & $\begin{array}{l}(-0.327 \\
0.248)\end{array}$ & $\begin{array}{l}(-0.206 \\
0.397)\end{array}$ \\
\hline \multicolumn{9}{|l|}{ Psychological } \\
\hline Sample & -0.123 & 0.054 & 0.135 & 0.096 & 0.278 & 0.258 & 0.054 & 0.109 \\
\hline Bootstrap bias & 0.004 & 0.002 & -0.003 & -0.008 & 0.002 & -0.007 & -0.006 & -0.006 \\
\hline $95 \% \mathrm{Cl}$ & $\begin{array}{l}(-0.411, \\
0.207)\end{array}$ & $\begin{array}{l}(-0.257 \\
0.357)\end{array}$ & $\begin{array}{l}(-0.177 \\
0.430)\end{array}$ & $\begin{array}{l}(-0.237 \\
0.38 I)\end{array}$ & $\begin{array}{l}(-0.082 \\
0.608)\end{array}$ & $\begin{array}{l}(-0.035 \\
0.524)\end{array}$ & $\begin{array}{l}(-0.274 \\
0.354)\end{array}$ & $\begin{array}{l}(-0.203 \\
0.419)\end{array}$ \\
\hline \multicolumn{9}{|l|}{ Social } \\
\hline Sample & 0.143 & 0.190 & $0.37 I^{*}$ & 0.242 & 0.204 & 0.023 & -0.109 & $0.321^{*}$ \\
\hline Bootstrap bias & -0.020 & -0.005 & -0.007 & -0.003 & -0.010 & -0.004 & 0.004 & -0.008 \\
\hline $95 \% \mathrm{Cl}$ & $\begin{array}{l}(-0.230 \\
0.424)\end{array}$ & $\begin{array}{l}(-0.163 \\
0.509)\end{array}$ & $\begin{array}{l}(0.048, \\
0.624)\end{array}$ & $\begin{array}{l}(-0.065 \\
0.524)\end{array}$ & $\begin{array}{l}(-0.128 \\
0.491)\end{array}$ & $\begin{array}{l}(-0.290 \\
0.329)\end{array}$ & $\begin{array}{l}(-0.416 \\
0.232)\end{array}$ & $\begin{array}{l}(0.004 \\
0.571)\end{array}$ \\
\hline \multicolumn{9}{|l|}{ Environment } \\
\hline Sample & 0.163 & $0.325^{*}$ & 0.284 & $0.438 * *$ & 0.235 & $0.348^{*}$ & 0.152 & 0.282 \\
\hline Bootstrap bias & -0.001 & -0.009 & -0.005 & -0.004 & -0.013 & 0.001 & -0.001 & 0.000 \\
\hline $95 \% \mathrm{Cl}$ & $\begin{array}{l}(-0.155 \\
0.478)\end{array}$ & $\begin{array}{l}(0.007, \\
0.580)\end{array}$ & $\begin{array}{l}(-0.056 \\
0.598)\end{array}$ & $\begin{array}{l}(0.147, \\
0.677)\end{array}$ & $\begin{array}{l}(-0.099 \\
0.532)\end{array}$ & $\begin{array}{l}(0.052, \\
0.597)\end{array}$ & $\begin{array}{l}(-0.142 \\
0.43 I)\end{array}$ & $\begin{array}{l}(-0.025 \\
0.550)\end{array}$ \\
\hline \multicolumn{9}{|l|}{ Coping ${ }^{a}$} \\
\hline \multicolumn{9}{|l|}{ Social support } \\
\hline Sample & $0.437^{* *}$ & 0.116 & 0.045 & 0.054 & 0.070 & 0.162 & 0.019 & 0.272 \\
\hline Bootstrap bias & -0.009 & 0.000 & -0.003 & 0.008 & -0.005 & -0.009 & -0.002 & 0.001 \\
\hline $95 \% \mathrm{Cl}$ & $\begin{array}{l}(0.167 \\
0.672)\end{array}$ & $\begin{array}{l}(-0.220 \\
0.475)\end{array}$ & $\begin{array}{l}(-0.295 \\
0.373)\end{array}$ & $\begin{array}{l}(-0.282 \\
0.386)\end{array}$ & $\begin{array}{l}(-0.246 \\
0.378)\end{array}$ & $\begin{array}{l}(-0.138 \\
0.476)\end{array}$ & $\begin{array}{l}(-0.320 \\
0.338)\end{array}$ & $\begin{array}{l}(-0.077 \\
0.564)\end{array}$ \\
\hline \multicolumn{9}{|l|}{ Problem solving } \\
\hline Sample & -0.007 & -0.123 & -0.092 & -0.054 & $0.358^{*}$ & 0.175 & 0.248 & -0.066 \\
\hline Bootstrap bias & 0.002 & 0.003 & 0.002 & 0.007 & -0.004 & -0.006 & -0.001 & 0.000 \\
\hline $95 \% \mathrm{Cl}$ & $\begin{array}{l}(-0.297 \\
0.309)\end{array}$ & $\begin{array}{l}(-0.415 \\
0.191)\end{array}$ & $\begin{array}{l}(-0.404 \\
0.226)\end{array}$ & $\begin{array}{l}(-0.377 \\
0.293)\end{array}$ & $\begin{array}{l}(0.006 \\
0.628)\end{array}$ & $\begin{array}{l}(-0.164 \\
0.473)\end{array}$ & $\begin{array}{l}(-0.074 \\
0.524)\end{array}$ & $\begin{array}{l}(-0.399 \\
0.273)\end{array}$ \\
\hline \multicolumn{9}{|l|}{ Avoidance } \\
\hline Sample & 0.057 & -0.017 & -0.182 & -0.082 & 0.094 & 0.231 & 0.184 & 0.188 \\
\hline Bootstrap bias & 0.000 & 0.000 & -0.002 & -0.009 & 0.011 & 0.014 & -0.002 & -0.004 \\
\hline $95 \% \mathrm{Cl}$ & $\begin{array}{l}(-0.240 \\
0.361)\end{array}$ & $\begin{array}{l}(-0.332 \\
0.295)\end{array}$ & $\begin{array}{l}(-0.439 \\
0.115)\end{array}$ & $\begin{array}{l}(-0.377 \\
0.194)\end{array}$ & $\begin{array}{l}(-0.198 \\
0.390)\end{array}$ & $\begin{array}{l}(-0.092 \\
0.5 \mid 2)\end{array}$ & $\begin{array}{l}(-0.095 \\
0.463)\end{array}$ & $\begin{array}{l}(-0.165 \\
0.473)\end{array}$ \\
\hline \multicolumn{9}{|l|}{ Positive thinking } \\
\hline Sample & -0.158 & -0.144 & 0.025 & 0.193 & 0.27 I & 0.163 & $0.400 * *$ & 0.046 \\
\hline Bootstrap bias & 0.002 & 0.007 & 0.011 & -0.001 & -0.007 & 0.002 & -0.003 & -0.001 \\
\hline $95 \% \mathrm{Cl}$ & $\begin{array}{l}(-0.455 \\
0.152)\end{array}$ & $\begin{array}{l}(-0.434 \\
0.182)\end{array}$ & $\begin{array}{l}(-0.259, \\
0.322)\end{array}$ & $\begin{array}{l}(-0.144, \\
0.495)\end{array}$ & $\begin{array}{l}(-0.067 \\
0.556)\end{array}$ & $\begin{array}{l}(-0.185 \\
0.470)\end{array}$ & $\begin{array}{l}(0.073 \\
0.688)\end{array}$ & $\begin{array}{l}(-0.243 \\
0.357)\end{array}$ \\
\hline
\end{tabular}

Notes: a ${ }^{2}$ oping strategies from the BriefCope questionnaire. $* P<0.05$, $* * P<0.01$.

Abbreviations: WHOQoL, World Health Organization Quality of Life; Cl, confidence interval; BriefCope, Brief Coping Orientation to Problems Experienced Scale. 


\section{Discussion}

This is the first study to assess whether QoL of age-related hearing impaired individuals and their caregivers is influenced by the coping strategies implemented either by themselves or their relatives.

The first finding of this study indicated that QoL of individuals with age-related hearing impairment was affected on the social dimension in comparison with French age- and sex-matched norms. Indeed, it is well documented that the consequences of hearing impairment include the inability to interpret speech sounds, which often produces a reduced ability to communicate; impairs physical and social functions; and leads to cognitive deficits, mood disturbances, and stigmatization. ${ }^{3-7}$ However, this study highlighted that the social dimension of QoL of the closest caregiver of these individuals is also significantly impacted. Closely participating in the daily life of an individual with age-related hearing impairment may be difficult and hampering. The progressive social deprivation that the ARHL individual imposes on him/herself may entrain a broader social deprivation of their closest relatives, ${ }^{22,23}$ specifically in the situation in which the two individuals are partners. Because of the isolation of the ARHL individual, caregivers are deprived of some of their independence and freedom.

The second interesting result of this study was that the emotional status of beneficiaries and caregivers was quite close. The chronic status and progressive course of the impairment partially explained that people similarly adjust their emotional status when facing this situation. This finding is not in line with the literature which shows discrepancies between patients and caregivers in their anxiety and mood levels. Caregivers were more often anxious than patients with chronic diseases, ${ }^{24}$ cancer patients, ${ }^{25}$ and terminally ill patients. ${ }^{26}$ However, these studies reported dissimilar situations with life-threatening and toxic treatments that have rapid and important consequences on the everyday life of patients and their relatives.

Our study also showed that beneficiaries and their caregivers implemented similar coping strategies, using strategies based on problem solving and positive thinking more than strategies based on looking for social support or avoidance. This result suggests that people who know each other very well and who are faced with the same difficult event tend to cope with it similarly. However, the effectiveness of the employed coping strategies depends on the cognitive, behavioral, and social resources that the individuals are able to mobilize. Because of the progressive impairment process, individuals with ARHL and their caregivers have a long time to adapt and develop specific coping strategies. In the case of acute and severe disease, authors reported that patients usually begin to organize their lives more, accept their limitations, and find ways to manage limitations 6 months after the disease diagnosis, ${ }^{27}$ but only limited amounts of data are available concerning the strategies used by people with ARHL. ${ }^{28}$

While the influence of emotional distress on QoL of the individuals was expected, the relationships between the nature of the coping strategies used and their QoL level were less evident. Individuals who used active coping strategies, such as problem-solving or positive thinking strategies, reported higher QoL scores. Active coping strategies are thought to be better methods to address stressful events, and avoidant coping strategies appear to be a psychological risk factor for adverse responses to stressful life events. ${ }^{16}$ Developing a better understanding of the ways patients and their relatives support each other and cope together during stressful situations may aid in the development of couple-focused interventions. Our study encourages a systematic assessment of ARHL individuals and caregiver coping styles, to identify individuals who do not use healthy coping strategies, and offers targeted psychological interventions. Furthermore, cognitive training and psychosocial support may serve as important additions to hearing loss rehabilitation. ${ }^{29}$

Lastly, some researchers have shown the importance of investigating the ways that coping strategies implemented by individuals from a social group (couples, families, etc) influence outcomes among the other members of the group. In this study, regarding the interrelations within the dyads, we showed that the use of active coping strategies (problem solving and positive thinking) by the ARHL individual was linked to the use of passive coping strategies (avoidance and social support) by their caregivers. In the same way, we showed that a better QoL of each member of the dyad was associated with the use of passive coping strategies by the other member of the dyad. The two members likely run in opposition "as communicating vessels".

Some limitations should be considered. First, the representativeness of our sample should be discussed. The people involved in this study voluntarily chose to perform a health checkup, which indicated that they were concerned about prevention and health promotion. However, we know that a significant proportion of individuals with ARHL are in denial about their impairment, may be reluctant to seek help from the health care system, and do not wish to be managed. Replication of our findings in these groups is required. Second, the small sample size and exploratory nature of our analysis did not allow for a deeper investigation of several associations with QoL or coping, especially investigations regarding sociodemographics, hearing aid use, and the nature of the dyadic relationship. The degree of hearing loss and the cognitive decline should also be examined to better understand their 
influence on QoL of the individuals. The exploratory nature of this work allows scheduling larger studies integrating these various parameters. However, the bootstrapping ensured the robustness of our results. Third, the study employed an observational and cross-sectional design, which did not allow for causality inferences to be made between coping strategies and QoL. Thus, it remains unknown whether an individual's coping strategies actually influence QoL and that of his/her relatives over time. This study did not use specific dyadic analyses based on a specific actor-partner interdependence model specifically developed to study the dyadic relationships that integrate a conceptual view of interdependence in two-person relationships. ${ }^{30,31}$ People in a dyadic relationship strongly influence each other's cognitions, emotions, behaviors, and QoL. However, this approach preferentially requires a large sample size to assess effects within longitudinal designs.

\section{Conclusion}

This study emphasizes that QoL of individuals with agerelated hearing impairment and their natural caregivers is related to the coping strategies that they use. This finding suggests that targeted interventions should be offered to help individuals who experience emotional difficulties to implement more efficient coping strategies.

\section{Disclosure}

The authors report no conflicts of interest in this work.

\section{References}

1. Mathers C, Boerma T, Ma Fat D. The Global Burden of Disease, 2004 update. http://www.who.int/healthinfo/global_burden_disease/ GBD_report_2004update_full.pdf. Accessed August 22, 2016.

2. Haeusler L, de Laval T, Millot C. Étude quantitative sur le handicap auditif à partir de 1'enquête « Handicap-Santé »[Quantitative study on hearing loss from the "Handicap-Santé" survey]. Paris, France: Direction de la recherche, des études, de l'évaluation et des statistiques; 2014.

3. Murray CJL, Lopez AD. The Global Burden of Disease: A Comprehensive Assessment of Mortality and Disability from Diseases, Injuries and Risk Factors in 1990 and Projected to 2020 (Global Burden of disease and Injury Series). Vol 1. Harvard School of Public Health on behalf of the World Health Organization and the World Bank, Cambridge; 1996.

4. Dalton DS, Cruickshanks KJ, Klein BE, Klein R, Wiley TL, Nondahl DM. The impact of hearing loss on quality of life in older adults. Gerontologist. 2003;43(5):661-668.

5. Gilhome Herbst KR, Meredith R, Stephens SD. Implications of hearing impairment for elderly people in London and in Wales. Acta Otolaryngol Suppl. 1990;476:209-214.

6. Vesterager V, Salomon G, Jagd M. Age-related hearing difficulties. Part II. Psychological and sociological consequences of hearing problems - a controlled study. Audiology. 1988;27(3):179-192.

7. Salomon G. Hearing problems and the elderly. Dan Med Bull. 1986; 33(Supp1 3):1-22.

8. Mulrow CD, Aguilar C, Endicott JE, et al. Association between hearing impairment and the quality of life of elderly individuals. J Am Geriatr Soc. 1990;38(1):45-50.
9. Campbell VA, Crews JE, Moriarty DG, Zack MM, Blackman DK. Surveillance for sensory impairment, activity limitation, and healthrelated quality of life among older adults - United States, 1993-1997. MMWR CDC Surveill Summ. 1999;48(8):131-156.

10. Scarinci N, Worrall L, Hickson L. The effect of hearing impairment in older people on the spouse: development and psychometric testing of the significant other scale for hearing disability (SOS-HEAR). Int $J$ Audiol. 2009;48(10):671-683.

11. Hetu R, Jones L, Getty L. The impact of acquired hearing impairment on intimate relationships: implications for rehabilitation. Audiology. 1993;32(6):363-381.

12. Piercy SK, Piercy FP. Couple dynamics and attributions when one partner has an acquired hearing loss: implications for couple therapy. J Mar Fam Ther. 2002;28(3):315-326.

13. Wallhagen MI, Strawbridge WJ, Shema SJ, Kaplan GA. Impact of selfassessed hearing loss on a spouse: a longitudinal analysis of couples. J Gerontol Ser B Psychol Sci Soc Sci. 2004;59(3):S190-S196.

14. Lazarus M, Folkman S. Stress, Appraisal and Coping. New York, NY: Springer; 1984.

15. Folkman S, Moskowitz JT. Positive affect and the other side of coping. Am Psychologist. 2000;55(6):647-654.

16. Holahan CJ, Moos RH. Personal and contextual determinants of coping strategies. J Personal Soc Psychol. 1987;52(5):946-955.

17. Clark JG. Uses and abuses of hearing loss classification. ASHA. 1981; 23(7):493-500.

18. WHOQOL Group. Development of the World Health Organization WHOQOL-BREF quality of life assessment. The WHOQOL Group. Psychol Med. 1998;28(3):551-558.

19. Baumann C, Erpelding ML, Regat S, Collin JF, Briancon S. The WHOQOL-BREF questionnaire: French adult population norms for the physical health, psychological health and social relationship dimensions. Rev Epidemiol Sante Publique. 2010;58(1):33-39.

20. Carver CS. You want to measure coping but your protocol's too long: consider the Brief COPE. Int J Behav Med. 1997;4(1):92-100.

21. Muller L, Spitz E. Évaluation multidimensionnelle du coping: validation du Brief COPE sur une population française [Multidimensional assessment of coping: validation of the Brief COPE among French population]. Encephale. 2003;29(6):507-518. French.

22. Preminger JE, Meeks S. The influence of mood on the perception of hearing-loss related quality of life in people with hearing loss and their significant others. Int J Audiol. 2010;49(4):263-271.

23. Preminger JE, Meeks $\mathrm{S}$. The Hearing Impairment Impact-Significant Other Profile (HII-SOP): a tool to measure hearing loss-related quality of life in spouses of people with hearing loss. J Am Acad Audiol. 2012; 23(10):807-823.

24. Sneeuw KC, Sprangers MA, Aaronson NK. The role of health care providers and significant others in evaluating the quality of life of patients with chronic disease. J Clin Epidemiol. 2002;55(11):1130-1143.

25. Leroy T, Fournier E, Penel N, Christophe V. Crossed views of burden and emotional distress of cancer patients and family caregivers during palliative care. Psycho-oncology. Epub 2015 Dec 3.

26. Tang ST. Concordance of quality-of-life assessments between terminally ill cancer patients and their primary family caregivers in Taiwan. Cancer Nurs. 2006;29(1):49-57.

27. Molassiotis A, Wilson B, Brunton L, Chaudhary H, Gattamaneni R, McBain C. Symptom experience in patients with primary brain tumours: a longitudinal exploratory study. Eur J Oncol Nurs. 2010;14(5):410-416.

28. Wahl HW, Heyl V, Schilling O. Robustness of personality and affect relations under chronic conditions: the case of age-related vision and hearing impairment. J Gerontol Ser B Psychol Sci Soc Sci. 2012;67(6):687-696.

29. Heyl V, Wahl HW. Managing daily life with age-related sensory loss: cognitive resources gain in importance. Psychol Aging. 2012;27(2):510-521.

30. Campbell LJ, Kashy DA. Estimating actor, partner, and interaction effects for dyadic data using PROC MIXED and HLM5: a brief guided tour. Pers Relation. 2002;9:327-342.

31. Kashy DA, Kenny DA. The analysis of data from dyads and groups. Handbook of Research Methods in Social Psychology. New York, NY: Cambridge University Press; 1999. 
Patient Preference and Adherence

Dovepress

\section{Publish your work in this journal}

Patient Preference and Adherence is an international, peer-reviewed, open access journal that focuses on the growing importance of patient preference and adherence throughout the therapeutic continuum. Patient satisfaction, acceptability, quality of life, compliance, persistence and their role in developing new therapeutic modalities and compounds to optimize

Submit your manuscript here: http://www.dovepress.com/patient-preference-and-adherence-journ clinical outcomes for existing disease states are major areas of interest for the journal. This journal has been accepted for indexing on PubMed Central. The manuscript management system is completely online and includes a very quick and fair peer-review system, which is all easy to use. Visit http://www. dovepress.com/testimonials.php to read real quotes from published authors. 